REVIEW

\title{
Management of chronic hepatitis $C$
}

\author{
V Lo Re III, J R Kostman
}

Postgrad Med J 2005;81:376-382. doi: 10.1136/pgmj.2004.025403

Hepatitis $\mathrm{C}$ virus $(\mathrm{HCV})$ infection is transmitted primarily through percutaneous exposure to blood, and most infections are associated with injection drug use. Progression to chronic HCV occurs in $55 \%$ to $86 \%$ of infected people, and persistent infection is a major cause of cirrhosis, end stage liver disease, and hepatocellular carcinoma. The detection of HCV antibodies should be performed initially to screen at risk populations. In those who are seropositive, $\mathrm{HCV}$ viraemia should be assessed to determine if chronic HCV is present. The HCV genotype should also be determined, as this is the strongest predictor of response to available treatment. A liver biopsy is very often helpful because it can estimate degree of hepatic fibrosis, identify concurrent diseases that might contribute to hepatic injury, and aid in selection of patients for treatment. The decision to start antiviral therapy should take into account potential contraindications to therapy, patient motivation, severity of disease, age, and HCV genotype. Combination therapy with weekly subcutaneous pegylated interferon and daily oral ribavirin is the standard of care for treating patients with chronic HCV.

See end of article for authors' affiliations

\section{Correspondence to:} Dr V Lo Re III, Division of Infectious Diseases, Center for Clinical Epidemiology and Biostatistics, 502 Johnson Pavilion, University of Pennsylvania School of Medicine, Philadelphia, PA 19104, USA; vincent.lore@uphs. upenn.edu

Submitted 11 June 2004 Accepted for publication 13 August 2004
1 nfection with the hepatitis $\mathrm{C}$ virus (HCV) is a leading cause of liver disease worldwide. ${ }^{1}$ This disorder was first recognised in the mid-1970s and was categorised as "non-A, non-B hepatitis". ${ }^{2}$ HCV was subsequently identified in 1988 as a ribonucleic acid (RNA) virus, ${ }^{3}$ and it can cause persistent infection in susceptible hosts after parenteral or percutaneous transmission. ${ }^{45}$ Progression to chronic hepatitis $\mathrm{C}$ occurs in most people acutely infected with HCV, and persistent infection is an important cause of cirrhosis, end stage liver disease, and hepatocellular carcinoma. ${ }^{167}$ Liver disease attributable to $\mathrm{HCV}$ currently represents the main indication for liver transplantation. ${ }^{58}$ Thus, early detection and treatment is of great importance.

Primary care physicians play a key part in the management of patients with chronic HCV by (1) identifying those chronically infected with the virus, (2) educating such people about the nature of the disease (particularly transmission, progression, and interaction with alcohol), and (3) assisting in treatment decisions. This article reviews the epidemiology, natural history, and clinical characteristics of chronic HCV infection to better assist clinicians in this endeavour. The diagnostic evaluation and current treatment regimens are also discussed.

\section{SCOPE OF THE PROBLEM}

Infection with HCV is an important public health problem in both developing and developed countries. ${ }^{1}$ Despite the introduction of laboratory tests to screen national blood supplies, HCV remains the most common cause of post-transfusion hepatitis worldwide because unscreened blood and blood products are still used in many developing countries or economies in transition. ${ }^{19-11}$ The World Health Organisation estimates that 200 million people, or about $3 \%$ of the world's population, have been infected with $\mathrm{HCV}$, making this one of the most common blood borne infections globally. ${ }^{9-11}$ However, most people are asymptomatic and unaware that they are infected. About 170 million people are estimated to be living with chronic HCV and are at risk of advanced liver disease. ${ }^{9-11}$ Three to four million new HCV infections occur each year, and about 250000 annual deaths throughout the world result from HCV associated chronic liver disease. ${ }^{1}$ As knowledge of the infection continues to increase among the general public, more people will probably be tested for and diagnosed with chronic HCV in the future.

\section{NATURAL HISTORY AND CLINICAL FEATURES OF CHRONIC HCV}

In up to $45 \%$ of cases, acute HCV infection completely resolves, and this seems to be associated with a younger age at infection, female sex, and possibly certain major histocompatibility complex genes. ${ }^{6-8} 12$ However, about $55 \%$ to $86 \%$ of HCV infected patients develop chronic infection, manifested by the persistence of detectable HCV in the serum, and this has been primarily attributed to the propensity of HCV to mutate and evade host defences..$^{6-8} 1314$

Chronic HCV is usually characterised by a lack of symptoms or only fatigue or vague abdominal pain. Extrahepatic manifestations of chronic HCV may be identified, and these are associated primarily with autoimmune or lymphoproliferative states (table 1$).{ }^{15}$ Increases in serum alanine aminotransferase (ALT) reflect hepatocyte injury, but these values typically fluctuate over time and may be even normal on occasion. ${ }^{5}$

The major complication of chronic HCV infection is progressive hepatic fibrosis leading to cirrhosis, which develops in about $20 \%$ of those with chronic HCV. ${ }^{67}$ The natural history of chronic HCV is variable, and progression of chronic liver disease is insidious in most patients. About one third of patients with chronic HCV develop hepatic cirrhosis 15 to 20 years after infection ("rapid fibrotic progressors"), one third

Abbreviations: $\mathrm{HCV}$, hepatitis $\mathrm{C}$ virus; $\mathrm{RNA}$, ribonucleic acid; ALT, alanine aminotransferase 
Box 1 Extrahepatic manifestations of chronic hepatitis $\mathrm{C}$ virus infection

Autoimmune diseases

- Arthritis

- Autoimmune thyroiditis

- Diabetes mellitus

- Idiopathic thrombocytopenic purpura

- Myasthenia gravis

- Sjögren's syndrome

Dermatological manifestations

- Erythema multiforme

- Erythema nodosum

- Lichen planus

- Porphyria cutanea tarda

- Pruritus

- Psoriasis

- Vasculitis

Haematological disorders

- Aplastic anaemia

- Essential mixed (type II) cryoglobulinaemia

- Monoclonal gammopathy

- Non-Hodgkin's lymphoma

Neurological disease

- Peripheral neuropathy

Ocular diseases

- Mooren's corneal ulcers

- Scleritis

- Uveitis

Pulmonary disease

- Idiopathic pulmonary fibrosis

Renal disease

- Membranoproliferative glomerulonephritis

develop cirrhosis 20 to 30 years after infection ("intermediate fibrotic progressors"), and one third develop it only after 30 years of HCV infection ("slow fibrotic progressors"). ${ }^{16}$ Patients with persistently normal values of serum ALT have a lower risk for fibrotic progression. ${ }^{17}$ However, a number of factors can accelerate progression to advanced liver disease, most notably alcohol consumption, ${ }^{17-22}$ coinfection with HIVV $^{23-26}$ or hepatitis B virus, ${ }^{27}{ }^{28}$ and older age at the time of infection. ${ }^{14}{ }^{17}$ In particular, heavy alcohol intake ( $>50$ grams per day) in patients with chronic HCV has been shown to increase fibrosis progression, rates of cirrhosis, and risk of death. ${ }^{17-22}$ The adverse effects of light and moderate amounts of alcohol intake on HCV infection have not been thoroughly evaluated, but one retrospective study assessing patients who drank less than 40 grams per day of alcohol found that fibrosis correlated with greater alcohol use and more frequent drinking. ${ }^{29}$ Obesity and hepatic steatosis are also emerging independent predictors of more severe liver fibrosis. ${ }^{30-35}$

Chronic HCV infection is associated with an increased risk of hepatocellular carcinoma, but this occurs primarily in patients with cirrhosis. ${ }^{45}{ }^{36}$ Factors that increase the risk of hepatocellular carcinoma among HCV infected people include male sex, ${ }^{36}$ older age, ${ }^{36}$ chronic hepatitis B infection, ${ }^{28} 36{ }^{37}$ and heavy alcohol ingestion ( $>50$ grams/day). ${ }^{22} 3638$ Once cirrhosis is established, the incidence of hepatocellular carcinoma is $1 \%$ to $4 \%$ per year. ${ }^{39}$ Death from chronic HCV typically occurs because of decompensated cirrhosis or hepatocellular carcinoma. Figure l summarises the natural history of HCV infection.

\section{APPROACH TO THE EVALUATION OF THE PATIENT WITH HEPATITIS C}

A systematic approach to the evaluation of patients with HCV infection should include an assessment of pertinent risk factors for HCV transmission; a thorough history emphasising concomitant medical illnesses, ongoing substance misuse, and neuropsychiatric disorders; and a careful physical examination to identify stigmata of end stage liver disease. Additional laboratory tests should then be performed to further determine the need for antiviral therapy.

\section{Risk factors for HCV infection}

Primary care physicians should obtain a history of high risk exposures associated with the transmission of HCV. HCV is transmitted primarily through percutaneous exposure to blood, ${ }^{12}{ }^{40-42}$ and risk factors associated with transmission of HCV include:

- Injection and other illicit drug use-currently, most new HCV infections are associated with injection drug use, and this accounts for about $60 \%$ of HCV transmission. ${ }^{43}$ About $65 \%$ of injection drug users are infected within one year of initiation of injection behaviour. ${ }^{44}$ Intranasal cocaine use has also been associated with acquisition of HCV. ${ }^{7}$

- Transfusion and organ transplantation-the introduction of HCV antibody testing in 1992 made transmission of HCV by these routes rare, but recipients of blood transfusions and organ transplants before this date remain at particular risk. $^{45}$

- Haemodialysis - the prevalence of HCV antibodies among haemodialysis patients is about $8 \%{ }^{46}$ and the infection is presumed to have been transmitted by inadequate infection control practices. ${ }^{40}$

- Health care workers-needlestick injury is the primary risk factor for HCV transmission among health care workers, and the incidence of seroconversion after such an injury is $3 \%$ to $4 \% .{ }^{87}$ Transmission of HCV from blood splash to the conjunctiva has also been reported. ${ }^{48} 49$

- Sexual activity - sexual transmission of HCV occurs at low frequency. Based on seroprevalence studies using genotyping or sequence analysis to evaluate antibody concordant couples, the estimated prevalence of HCV among heterosexual couples in monogamous relationships is $2.8 \%$ to $11 \%$ in south east Asia, $0 \%$ to $6.3 \%$ in northern Europe, and $2.7 \%$ in the USA. ${ }^{50}$ In addition, persons in long term monogamous relationships are at lower risk of HCV acquisition ( $0 \%$ to $0.6 \%$ per year) compared with persons with multiple partners or those at risk for sexually transmitted diseases $(0.4 \%$ to $1.8 \%$ per year $) .^{50}$ This difference may reflect differences in sexual risk behaviours or in rates of exposure to non-sexual sources of HCV, such as injection drug use, intranasal cocaine use, tattooing, or sharing of razors and toothbrushes. ${ }^{50}$ Monogamous couples do not need to use barrier protection but should be advised that condoms may reduce the already low risk of HCV transmission. ${ }^{12}{ }^{40-42} \mathrm{HCV}$ infected people who have multiple sexual partners or who are in short term relationships should be advised to use condoms to prevent the transmission of HCV (as well as other sexually transmitted diseases). ${ }^{12} 40-42$ 


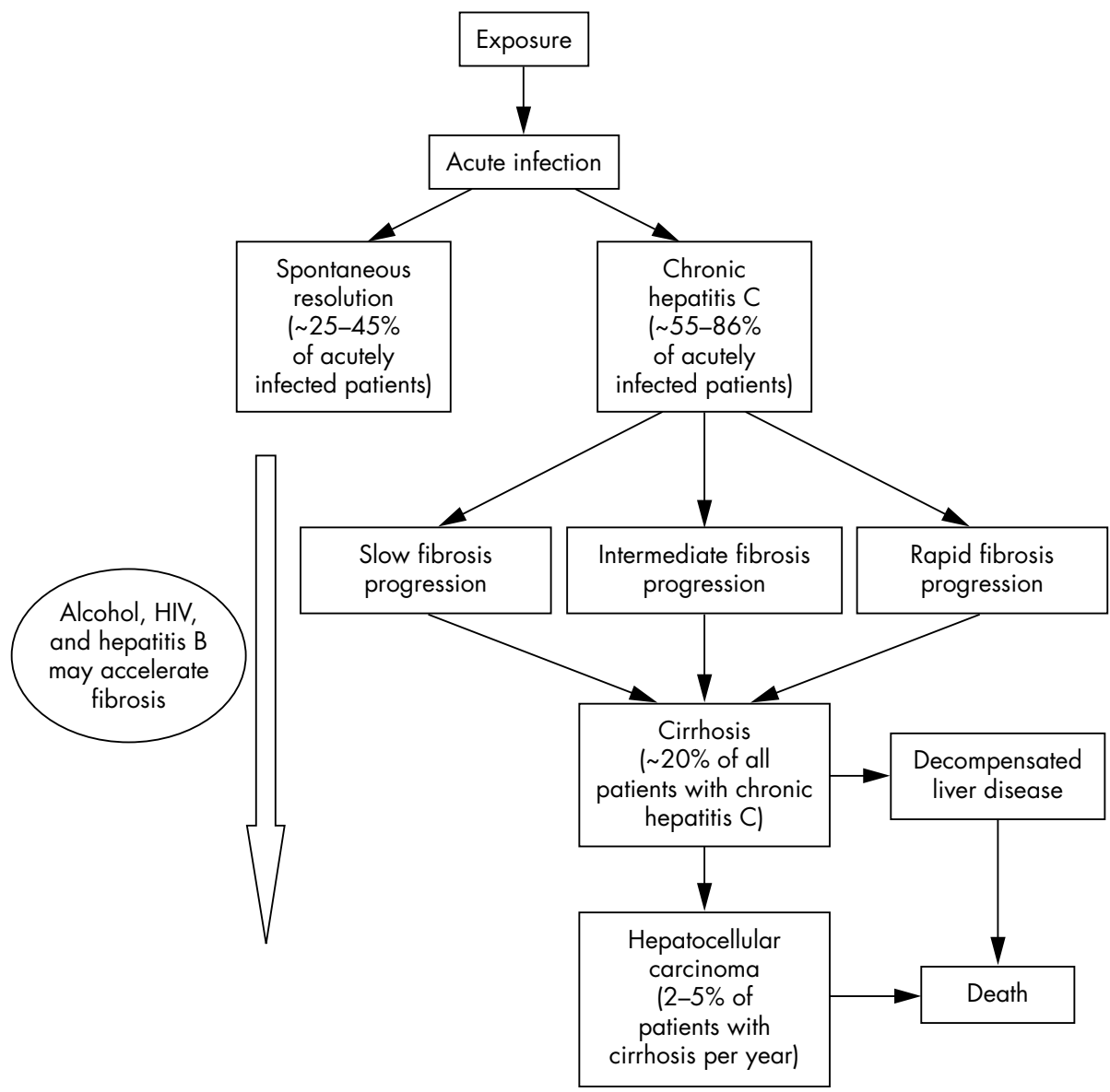

Figure 1 Natural history of hepatitis C virus infection. Adapted from National Institutes of Health Consensus

Development Conference Statement:

Management of hepatitis C: 2002-June

10-12, 2002. Hepatology

2002;36(suppl 1): S3-20.

- Tattooing/body piercing - contaminated equipment or supplies associated with these activities have been implicated in HCV transmission. ${ }^{751}$

- Vertical transmission - the incidence of HCV infection is 5\% to $6 \%$ among infants born to HCV infected women, ${ }^{52}$ but the incidence rises to about $20 \%$ among children born to mothers coinfected with both HCV and HIV..$^{53}$ Infants born to HCV infected women should have their blood tested for either HCV RNA at six months of age or HCV antibody at 15 months of age (after maternal antibodies have waned). ${ }^{12}$ Breast feeding does not seem to transmit HCV. ${ }^{54}$

- Alternative routes of transmission-there is no evidence that casual contact, such as kissing, hugging, or sharing eating utensils, is associated with HCV transmission. ${ }^{12}{ }^{40-42}$ However, sharing household items that may be contaminated with blood, such as razors, toothbrushes, or nail grooming equipment, should be avoided. $.^{12} 40-42$

\section{History and physical examination}

Clinicians should identify symptoms that may be attributable to chronic HCV, such as lethargy, malaise, abdominal pain, and arthralgias, as well as symptoms of severe liver disease (such as confusion, easy bruising, and ascites). Ongoing drug and alcohol misuse that could exacerbate liver damage associated with chronic HCV and lead to lack of adherence to HCV therapy should also be determined. ${ }^{12} 4142$ Comorbid conditions that might influence the suitability for treatment, such as neuropsychiatric illnesses, cardiovascular disease, and autoimmune disorders, should also be ascertained during the initial assessment. ${ }^{55}$ Physical examination should focus on identifying any stigmata of advanced liver disease.

\section{Laboratory evaluation}

A number of tests are useful in the evaluation of $\mathrm{HCV}$ infection:

- HCV antibody - the detection of HCV antibodies is recommended as the initial test for the identification of HCV and is useful for screening at risk populations. ${ }^{12}$ Box 2 lists the patients who should be considered for HCV screening.

\section{Box 2 Patients for whom HCV testing is} recommended*

- Persons who have injected illicit drugs (even only once)

- Persons with conditions associated with a high prevalence of $\mathrm{HCV}$ infection:

- HIV infection

- Haemophilia (especially if received clotting factor concentrates before 1987)

- Haemodialysis

- Unexplained abnormal aminotransferase activities

- Children born to HCV infected mothers

- Health care, emergency, and public safety workers who experience a needlestick or mucosal exposure to $\mathrm{HCV}$ positive blood

- Current sexual partners of HCV infected persons

*Adapted from Strader DB et al. Hepatology 2004;39: 11 14771 
The primary serological test used for the detection of HCV antibody is an enzyme immunoassay (third generation), which is comparatively inexpensive, reproducible, and carries a high sensitivity (99\%) and specificity (99\%). ${ }^{12}$ It can detect antibodies 4 to 10 weeks after infection. ${ }^{8}$ A negative enzyme immunoassay is usually sufficient to exclude the diagnosis of HCV infection in immunocompetent patients. ${ }^{12}$ However, the test can be falsely negative in those with immunodeficiencies or end stage renal disease. ${ }^{812}$ Once patients seroconvert, they usually remain positive for HCV antibody. ${ }^{8}$ Thus, the presence of HCV antibody may reflect remote or recent infection.

- HCV RNA assays - assays based on the molecular detection of HCV using polymerase chain reaction or other gene amplification techniques are available. A qualitative HCV RNA assay can confirm viraemia in patients with a positive enzyme immunoassay result as well as in those with a negative test in whom infection is still suspected. ${ }^{8}$ The quantitative HCV RNA assay can help predict treatment response (patients with HCV viral loads exceeding 2 million copies $/ \mathrm{ml}$ (or $800000 \mathrm{IU} / \mathrm{ml}$ ) respond less well to treatment) and is useful in monitoring the response to HCV therapy. ${ }^{12}{ }^{55} 56$ However, HCV RNA values provide no information about disease severity or risk of progression, so serial monitoring of HCV viral loads in untreated patients is unnecessary.

- ALT and assessment of liver function-ALT activities may be useful in monitoring HCV infection but are insensitive in predicting disease progression to cirrhosis. ${ }^{57}$ ALT activities may be normal or fluctuate in those with HCV infection, and a single normal value does not exclude active infection, progressive liver disease, or cirrhosis. ${ }^{57}$ Liver function tests, which include prothrombin time, bilirubin, and albumin, should also be performed.

- Genotype-worldwide, six genetically distinct groups of HCV isolates, called genotypes (numbered 1 through 6), have been identified. ${ }^{56}$ There is little difference in the mode of transmission or natural history of infection among the different genotypes. However, cure rates with antiviral therapy are notably higher with genotypes 2 and 3, and the duration of HCV therapy is shorter for these genotypes. ${ }^{58}$ Thus, HCV genotype is an important parameter to determine in the evaluation of chronic HCV infection. Genotype does not change during the course of infection and should only be evaluated once. ${ }^{5}$

- Liver biopsy - as ALT abnormalities cannot accurately predict the degree of hepatic inflammation and fibrosis, ${ }^{57}$ histological evaluation of a liver biopsy specimen remains the gold standard for reliably estimating the stage of hepatic fibrosis and degree of hepatic inflammation in patients with chronic HCV. ${ }^{12} 4142575960$ Thus, the liver biopsy can determine the relative urgency of HCV therapy. The most validated method for evaluating the degree of hepatic fibrosis is the METAVIR classification system, which divides liver fibrosis into five discrete stages $(0=$ no fibrosis; $1=$ mild fibrosis (portal fibrosis without septae); $2=$ moderate fibrosis (a few septae); $3=$ severe fibrosis (numerous septae without cirrhosis), $4=$ cirrhosis). ${ }^{60} \mathrm{~A}$ liver biopsy may identify concurrent disease processes (for example, steatosis, iron overload) that can contribute to hepatic injury. It aids in the selection of chronic HCV patients for treatment and helps to correctly time therapeutic interventions. ${ }^{56}$ The liver biopsy can also determine the presence of cirrhosis, which may increase the risk of toxicity with therapy even in HCV genotypes 2 and 3. Clinicians routinely obtain a liver biopsy in patients with HCV genotype 1 infection to guide recommendations for treatment. As patients infected with HCV genotypes 2 or 3 have a high likelihood of response, some advocate treating such patients without a liver biopsy. ${ }^{12}{ }^{42}$

- HIV screening-many risk factors for HCV transmission are shared by HIV infection. ${ }^{75}$ However, results from a recent cross sectional study show that a high percentage of HCV infected patients are not being tested for HIV. ${ }^{61}$ Patients with HCV who are at risk for HIV should be offered testing with appropriate pre-test and post-test counselling.

- Hepatitis A and B screening-as coinfection with hepatitis B virus accelerates the progression to cirrhosis 28 and increases the risk of hepatocellular carcinoma, ${ }^{28} 3637$ patients with chronic HCV should also undergo serological testing for hepatitis B virus. Hepatitis A serology should also be performed as superinfection with this virus could result in higher morbidity. ${ }^{62}$

- Hepatocellular carcinoma screening-patients with HCV induced cirrhosis may be evaluated for hepatocellular carcinoma with a serum $\alpha$ fetoprotein and abdominal ultrasound every six months, ${ }^{63}$ although data on the optimal screening strategy are lacking.

- Antinuclear antibody - patients with chronic HCV infection have been found to have a higher rate of autoantibodies in the serum. ${ }^{64}$ As a result, determination of the antinuclear antibody has been recommended before starting HCV therapy. ${ }^{55}$ Although the presence of an antinuclear antibody does not adversely affect the outcome of HCV therapy, such patients should be monitored carefully for the development of autoimmune diseases (for example, thyroiditis, rheumatoid arthritis, and psoriasis) during the use of interferon. ${ }^{65}$

- Thyroid function tests-thyroid disorders are common in patients with chronic HCV, and interferon induced thyroid disease is among the most common adverse events associated with HCV treatment. ${ }^{66}$ Thyroid stimulating hormone concentrations should therefore be checked before starting HCV therapy. ${ }^{55}$

\section{TREATMENT OF CHRONIC HCV INFECTION}

\section{Support and education}

Support and education are central to the management of patients with chronic HCV, and healthcare providers should distribute additional educational materials and offer referral to support groups to those undergoing evaluation for established HCV infection. Patients with chronic HCV should be referred to an infectious diseases physician or hepatologist

Table 1 Possible adverse effects of pegylated interferon and ribavirin therapy*

\begin{tabular}{|c|c|}
\hline Pegylated interferon & Ribavirin \\
\hline $\begin{array}{l}\text { Alopecia } \\
\text { Anaemia } \\
\text { Autoantibodies } \\
\text { Bronchospasm } \\
\text { Depression/mood lability } \\
\text { Diarrhoea } \\
\text { Influenza-like symptoms (headaches, } \\
\text { fatigue, fever, myalgias, arthralgias, } \\
\text { anorexia) } \\
\text { Injection site pain/erythema } \\
\text { Loss of libido } \\
\text { Retinopathy } \\
\text { Sleep disturbances } \\
\text { Thrombocytopenia } \\
\text { Thyroid dysfunction (hyperthyroidism } \\
\text { hypothyroidism) } \\
\text { Weight loss }\end{array}$ & $\begin{array}{l}\text { Cough, dyspnea } \\
\text { Gout } \\
\text { Haemolytic anaemia } \\
\text { Insomnia } \\
\text { Nausea } \\
\text { Pharyngitis } \\
\text { Pruritus } \\
\text { Rash } \\
\text { Teratogenicity }\end{array}$ \\
\hline
\end{tabular}


with expertise in HCV to provide more information about diagnosis, natural history, and therapeutic options. Clinical management should subsequently be multidisciplinary, with input from advanced practice nurses, psychiatrists, pharmacists, dietitians, and addiction management experts.

\section{Treatment of neuropsychiatric disorders}

Neuropsychiatric disorders, particularly depression, are common among patients with chronic HCV and are frequent adverse effects of interferon therapy. ${ }^{67}{ }^{68}$ Identification and treatment of neuropsychiatric disorders should be pursued before and during HCV therapy. ${ }^{12}$ Referral to a psychiatrist should also be considered.

\section{Immunisation against hepatitis $A$ and $B$}

As acute infection with hepatitis A or B in those with underlying chronic HCV infection can result in high morbidity, ${ }^{28}{ }^{62}$ hepatitis $\mathrm{A}$ and $\mathrm{B}$ vaccination should be performed in those who are seronegative for these viruses. These vaccines are safe and effective in patients with chronic HCV and may prevent poor outcomes. ${ }^{55}$

\section{Avoidance of hepatotoxins}

Heavy alcohol consumption can worsen the course and outcome of chronic HCV and may seriously compromise treatment by decreasing adherence or interfering with the antiviral action of interferon based therapy. ${ }^{22}$ Efforts to diagnose and treat alcohol misuse should be performed before beginning HCV therapy. Treatment for drug and alcohol misuse should be made available to all patients who want and need it. Data are inadequate to provide definitive recommendations regarding the effect of light to moderate alcohol use in patients with chronic HCV. Safe levels of alcohol consumption in patients with chronic HCV remain unclear, and even moderate levels of consumption may accelerate disease progression. ${ }^{12}$ Alcohol abstinence is therefore recommended before and during therapy. ${ }^{12} 41$ In addition, the use of all over the counter drugs and herbal agents that may have hepatotoxic effects should also be determined. ${ }^{69}$

\section{Pegylated interferon and ribavirin therapy}

Combination therapy with pegylated interferon and ribavirin (Copegus, Hoffmann-La Roche; Rebetol, Schering-Plough) is currently the standard of care for treating patients with chronic HCV. The primary goal of treatment is to eradicate (that is, cure) chronic HCV, ${ }^{12} 4142$ but therapy can also

\begin{tabular}{ll}
$\begin{array}{l}\text { Table } 2 \text { Potential contraindications to pegylated } \\
\text { interferon and ribavirin* }\end{array}$ \\
\hline Contraindications \\
\hline Pegylated interferon & Active substance misuse (particularly alcohol) \\
& Autoimmune disorders \\
& Decompensated cirrhosis \\
& Hyperthyroidism \\
& Neutropenia \\
& Pregnancy \\
& Severe psychiatric disease \\
& Thrombocytopenia \\
& Uncontrolled diabetes mellitus \\
& Uncontrolled hypertension \\
& Uncontrolled seizure disorder \\
& Anaemia \\
& Cerebrovascular disease \\
Coronary artery disease \\
Ribavirin & End stage renal disease \\
& Haemoglobinopathies \\
& Pregnancy \\
\hline
\end{tabular}

*Adapted from Lauer GM, Walker BD. N Engl J Med 2001;345:41-52. decrease hepatic inflammation and fibrosis, slow disease progression, and reduce the risks for cirrhosis and hepatocellular carcinoma even in the absence of cure. ${ }^{70-74}$ Two types of pegylated interferons, pegylated interferon alfa-2a (Pegasys, Hoffmann-La Roche) and pegylated interferon alfa-2b (Peg-Intron, Schering-Plough), which differ in their pharmacokinetic and chemical properties, have been developed..$^{75}$ Both formulations are given weekly via subcutaneous injection. Ribavirin is dosed by weight for genotype 1 ( $1000 \mathrm{mg}$ per day if $<75 \mathrm{~kg}$ and $1200 \mathrm{mg}$ per day if $\geqslant 75 \mathrm{~kg}$ ), whereas $800 \mathrm{mg}$ per day is sufficient for genotypes 2 and 3 , regardless of weight. ${ }^{58}$

Cure is determined by a sustained virological response, defined as the absence of detectable HCV RNA six months after the withdrawal of HCV therapy. Pegylated interferon alfa-2a ( $180 \mu \mathrm{g}$ per week) plus ribavirin produces an overall sustained virological response rate of $56 \%$ to $63 \%,^{58}{ }^{76}$ while pegylated interferon alfa- $2 \mathrm{~b} \quad(1.5 \mu \mathrm{g} / \mathrm{kg}$ per week) plus ribavirin produces a similar sustained virological response rate of $54 \% .{ }^{77} \mathrm{HCV}$ genotypes 2 and 3 are more responsive to HCV therapy (cure rates $78 \%$ to $84 \%$ ) and require only six months of treatment compared with HCV genotype l (cure rates $42 \%$ to $52 \%$ ), which requires 12 months of therapy. ${ }^{587677}$ Referral to an infectious disease physician or hepatologist should be performed to ensure appropriate monitoring during therapy as there are a number of adverse effects associated with both drugs (table 1).

Among those who are coinfected with both HIV and chronic HCV, the efficacy and safety of HCV treatment with pegylated interferon and ribavirin has recently been determined. ${ }^{78-80}$ The AIDS pegasys ribavirin international coinfection trial (APRICOT) ${ }^{78}$ and the AIDS clinical trials group study $5071^{79}$ evaluated the use of pegylated interferon alfa-2a ( $180 \mu \mathrm{g}$ weekly for 48 weeks) plus ribavirin (different ribavirin dosing regimens were used in these studies). Subjects with HCV genotypes 2 and 3 were found to be more responsive to HCV therapy (cure rates $62 \%$ to $73 \%$ ) compared with those with HCV genotype 1 (cure rates 14\% to 29\%). A third study, the French ANRS HC-02 RIBAVIC trial, ${ }^{80}$ examined the use of pegylated interferon alfa-2b $(1.5 \mu \mathrm{g} / \mathrm{kg}$ weekly for 48 weeks) combined with ribavirin $800 \mathrm{mg}$ daily in $\mathrm{HIV} / \mathrm{HCV}$ coinfected patients. Cure rates in this trial were substantially lower, and subjects with HCV genotypes 2 or 3 had a sustained virological response rate of $43 \%$, while those with HCV genotype 1 had a sustained virological response rate of only $11 \%$. HCV therapy did not compromise treatment of HIV infection in these studies. Close monitoring for adverse effects during HCV therapy is strongly advised.

\section{Indications for chronic HCV therapy}

The decision to treat chronic HCV should be made on an individual basis and take into account potential contraindications to therapy (table 2), patient motivation and readiness, severity of disease, age, and HCV genotype.

Patients with chronic HCV who should be considered for treatment include those who have at least moderate fibrosis (that is, METAVIR stage $\geqslant 2$ ) on liver biopsy, HCV genotype 2 or 3, persistent symptoms (for example, fatigue), and extrahepatic manifestations. ${ }^{12} 4142$ Special attention should be given to people who traditionally have not been considered candidates for treatment, including those who are coinfected with HIV, have controlled depression, or have a history of substance misuse but are currently in recovery. Observation with regular follow up every 6-12 months is recommended for patients with HCV viraemia, raised or persistently normal ALT activities, but only minimal or no histological evidence of fibrosis. ${ }^{12}{ }^{42}$ A repeat liver biopsy in five years may be useful in these patients to assess the rate of progression of hepatic inflammation and fibrosis. ${ }^{81}$ 


\section{SUMMARY}

HCV is transmitted primarily through percutaneous exposure to blood, and most infections are associated with injection drug use. Progression to chronic hepatitis C occurs in 55\% to $86 \%$ of people acutely infected, and persistent infection is a leading cause of advanced liver disease. The detection of HCV antibodies should be performed initially to screen at risk populations. If this test is positive, an HCV RNA assay (to determine if chronic HCV is present) and an HCV genotype test (as genotype is the strongest predictor of response to therapy) should be performed. A liver biopsy can estimate the degree of hepatic fibrosis, identify concurrent disease processes that might contribute to hepatic injury, and aid in the selection of patients for treatment. Patients with chronic HCV should be counselled to reduce alcohol consumption, as it accelerates liver injury, and should be vaccinated against hepatitis $A$ and $B$ viruses, if seronegative for these infections. Combination therapy with weekly subcutaneous pegylated interferon and daily oral ribavirin is currently the standard of care for treating patients with chronic HCV. Close monitoring of patients during HCV therapy is required as there are a number of adverse effects associated with both drugs.

\section{Authors' affiliations}

V Lo Re III, Division of Infectious Diseases, Center for Clinical Epidemiology and Biostatistics, University of Pennsylvania School of Medicine, Philadelphia, USA

J R Kostman, University of Pennsylvania School of Medicine and Division of Infectious Diseases, Presbyterian Medical Center, Philadelphia, USA

Funding: none.

Conflicts of interest: none declared.

\section{REFERENCES}

1 Kim WR. Global epidemiology and burden of hepatitis C. Microbes Infect 2002;4:1219-25.

2 Feinstone SM, Kapikian AZ, Purcell RH, et al. Transfusion-associated hepatitis not due to viral hepatitis type A or B. N Engl J Med 1975;292:767-70.

3 Alter HJ, Purcell RH, Shih JW, et al. Detection of antibody to hepatitis C virus in prospectively followed transfusion recipients with acute and chronic non-A, non-B hepatitis. N Engl J Med 1989;321:1494-500.

4 Liang TJ, Rehermann B, Seeff LB, et al. Pathogenesis, natural history, treatment, and prevention of hepatitis C. Ann Intern Med 2000;132:296-305.

5 Poynard T, Yuen MF, Ratziu V, et al. Lancet 2003;362:2095-100.

6 Alter MJ, Kruszon-Moran D, Nainan OV, et al. The prevalence of hepatitis C virus infection in the United States, 1988 through 1994. N Engl J Med 1999;341:556-62.

7 Conry-Cantilena C, VanRaden M, Gibble J, et al. Routes of infection, viremia and liver disease in blood donors found to have hepatitis $C$ virus infection. N Engl J Med 1996;334:1691-6.

8 Laver GM, Walker BD. Hepatitis C virus infection. N Engl J Med $2001 ; 345: 41-52$

9 World Health Organisation. Hepatitis C. Wkly Epidemiol Rec 1997;72:65-9.

10 World Health Organisation. Hepatitis C-global prevalence (update). Wkly Epidemiol Rec 1999;74:425-7.

11 World Health Organisation. Hepatitis C-global prevalence (update). Wkly Epidemiol Rec 2000;75:18-19.

12 National Institutes of Health Consensus Development Conference Statement Management of hepatitis C: 2002-June 10-12, 2002. Hepatology 2002;36(suppl 1):S3-20

13 Kenny-Walsh E. Clinical outcomes after hepatitis $C$ infection from contaminated anti-D immune globulin. Irish Hepatology Research Group. N Engl J Med 1999;340:1228-33.

14 Seeff LB. Natural history of chronic hepatitis C. Hepatology 2002;36(suppl 1):S35-46.

15 Zignego AL, Brechot C. Extrahepatic manifestations of HCV infection: facts and controversies. J Hepatol 1999;31:369-76.

16 Alberti A, Chemello L, Benvegnu L. Natural history of hepatitis C. J Hepatol 1999;31(suppl 1):17-24.

17 Poynard T, Ratziu V, Charlotte F, et al. Rates and risk factors of liver fibrosis progression in patients with chronic hepatitis c. J Hepatol 2001;34:730-9

18 Poynard T, Bedossa P, Opolon P. Natural history of liver fibrosis progression in patients with chronic hepatitis C. The OBSVIRC, METAVIR, CLINIVIR, and DOSVIRC groups. Lancet 1997;349:825-32.

19 Wiley TE, McCarthy M, Breidi L, et al. Impact of alcohol on the histological and clinical progression of hepatitis $C$ infection. Hepatology 1998;28:805-9
20 Corrao G, Arico S. Independent and combined action of hepatitis C virus infection and alcohol consumption on the risk of symptomatic liver cirrhosis. Hepatology 1998;27:914-19.

21 Harris DR, Gonin R, Alter HJ, et al. The relationship of acute transfusionassociated hepatitis to the development of cirrhosis in the presence of alcohol abuse. Ann Intern Med 2001;134:120-4.

22 Peters MG, Terrault NA. Alcohol use and hepatitis C. Hepatology 2002;36(suppl 1):S220-5.

23 Benhamou $Y$, Bochet M, Di Martino V, et al. Liver fibrosis progression in human immunodeficiency virus and hepatitis $C$ virus coinfected patients. The Multivirc Group. Hepatology 1999;30:1054-8.

24 Di Martino V, Rufat P, Boyer N, et al. The influence of human immunodeficiency virus coinfection on chronic hepatitis $C$ in injection drug users: a long-term retrospective cohort study. Hepatology 2001;34:1193-9.

25 Graham CS, Baden $L R, Y \cup E$, et al. Influence of human immunodeficiency virus infection on the course of hepatitis $C$ virus infection: a meta-analysis. Clin Infect Dis 2001;33:562-9.

26 Ragni MV, Belle SH. Impact of human immunodeficiency virus infection on progression to end-stage liver disease in individuals with hemophilia and hepatitis C virus infection. J Infect Dis 2001;183:1112-15.

27 Tsai JF, Jeng JE, Ho MS, et al. Independent and additive effect modification of hepatitis $C$ and $B$ viruses infection on the development of chronic hepatitis. $J$ Hepatol 1996;24:271-6.

28 Zarski JP, Bohn B, Bastie A, et al. Characteristics of patients with dual infection by hepatitis B and C viruses. J Hepatol 1998;28:27-33

29 Westin J, Lagging LM, Spak F, et al. Moderate alcohol intake increases fibrosis progression in untreated patients with hepatitis $C$ virus infection. J Viral Hepat 2002;9:235-41.

30 Hourigan LF, Macdonald GA, Purdie D, et al. Fibrosis in chronic hepatitis C correlates significantly with body mass index and steatosis. Hepatology 1999;29:1215-19.

31 Adinolfi LE, Gambardella M, Andreana A, et al. Steatosis accelerates the progression of liver damage of chronic hepatitis $C$ patients and correlates with specific HCV genotype and visceral obesity. Hepatology 2001;33:1358-64.

32 Westin J, Nordlinder H, Lagging M, et al. Steatosis accelerates fibrosis development over time in hepatitis $C$ virus genotype 3 infected patients. $J$ Hepatol 2002;37:837-42.

33 Castera L, Hezode C, Roudot-Thoraval F, et al. Worsening of steatosis is an independent factor of fibrosis progression in untreated patients with chronic hepatitis C and paired liver biopsies. Gut 2003;52:288-92.

34 Ortiz V, Berenguer M, Rayon JM, et al. Contribution of obesity to hepatitis Crelated fibrosis progression. Am J Gastroenterol 2002;97:2408-14.

35 Hu KQ, Kyulo NL, Esrailian E, et al. Overweight and obesity, hepatic steatosis, and progression of chronic hepatitis $C$ : a retrospective study on a large cohort of patients in the United States. J Hepatol 2004;40:147-54.

36 El-Serag HB. Hepatocellular carcinoma and hepatitis $C$ in the United States. Hepatology 2002;36(suppl 1):S74-83.

37 Donato $F$, Tagger A, Chiesa R, et al. Hepatitis $B$ and $C$ virus infection, alcohol drinking, and hepatocellular carcinoma: a case-control study in Italy. Brescia HCC Study. Hepatology 1997;26:579-84.

38 Donato F, Tagger A, Gelatti U, et al. Alcohol and hepatocellular carcinoma: the effect of lifetime intake and hepatitis virus infections in men and women. Am J Epidemiol 2002;155:323-31.

39 Bruno S, Silini E, Crosignani A, et al. Hepatitis $C$ virus genotypes and risk of hepatocellular carcinoma in cirrhosis: a prospective study. Hepatology 1997; 25:754-8.

40 Centers for Disease Control and Prevention. Recommendations for prevention and control of hepatitis C virus (HCV) infection and HCV-related chronic disease. MMWR Morb Mortal Wkly Rep 1998;47:1-39.

41 Booth JC, O'Grady J, Neuberger J. Clinical guidelines on the management of hepatitis C. Gut 2001;49(suppl 1):11-21.

42 Strader DB, Wright T, Thomas DL, et al. Diagnosis, management, and treatment of hepatitis C. Hepatology 2004;39:1 147-71.

43 Flamm SL, Parker RA, Chopra S. Risk factors associated with chronic hepatitis $C$ virus infection: limited frequency of an unidentified source of transmission. Am J Gastroenterol 1998;93:597-600.

44 Garfein RS, Vlahov D, Galai N, et al. Viral infections in short-term injection drug users: the prevalence of the hepatitis $C$, hepatitis $B$, human immunodeficiency, and human T-lymphotropic viruses. Am J Public Health 1996:86:655-61.

45 Schreiber GB, Busch MP, Kleinman SH, et al. The risk of transfusiontransmitted viral infections. The retrovirus epidemiology donor study. N Engl J Med 1996;334:1685-90.

46 Tokars JI, Frank M, Alter MJ, et al. National surveillance of dialysis-associated diseases in the United States, 2000. Semin Dial 2002;15:162-71.

47 Sulkowski MS, Ray SC, Thomas DL. Needlestick transmission of hepatitis C. JAMA 2002;287:2406-13.

48 Sartori M, La Terra G, Aglietta M, et al. Transmission of hepatitis C via blood splash into conjunctiva. Scand J Infect Dis 1993;25:270-1.

49 Rosen HR. Acquisition of hepatitis $C$ by a conjunctival splash. Am J Infect Control 1997;25:242-7

50 Terrault NA. Sexual activity as a risk factor for hepatitis C. Hepatology 2002;36(suppl 1):S99-105.

51 Ko YC, Ho MS, Chiang TA, et al. Tattooing as a risk of hepatitis $\mathrm{C}$ virus infection. J Med Virol 1992;38:288-91.

52 Conte $D$, Fraquelli $M$, Prati $D$, et al. Prevalence and clinical course of chronic hepatitis $\mathrm{C}$ virus (HCV) infection and rate of $\mathrm{HCV}$ vertical transmission in a cohort of 15,250 pregnant women. Hepatology 2000;31:751-5.

53 Gibb DM, Goodall RL, Dunn DT, et al. Mother-to-child transmission of hepatitis $C$ virus: evidence for preventable peripartum transmission. Lancet 2000;356:904-7. 
54 Kumar RM, Shahul S. Role of breast-feeding in transmission of hepatitis C virus to infants of HCV-infected mothers. J Hepatol 1998;29:191-7.

55 Herrine SK. Approach to the patient with chronic hepatitis $C$ virus infection. Ann Intern Med 2002;136:747-57.

56 Rosenberg PM. Hepatitis C: a hepatologist's approach to an infectious disease. Clin Infect Dis 2001:33:1728-32.

57 Pradat $P$, Alberti A, Poynard T, et al. Predictive value of ALT levels for histologic findings in chronic hepatitis C: a European collaborative study. Hepatology 2002;36:973-7.

58 Hadziyannis SJ, Sette H Jr, Morgan TR, et al. Peginterferon-alpha2a and ribavirin combination therapy in chronic hepatitis $C$ : a randomized study of treatment duration and ribavirin dose. Ann Intern Med 2004; 140:346-55.

59 Saadeh S, Cammell G, Carey WD, et al. The role of liver biopsy in chronic hepatitis C. Hepatology 2001;33:196-200.

60 Bedossa P, Poynard T. An algorithm for the grading of activity in chronic hepatitis C. The METAVIR Cooperative Study Group. Hepatology 1996;24:289-93.

61 Krain A, Wisnivesky JP, Garland E, et al. Prevalence of human immunodeficiency virus testing in patients with hepatitis $B$ and $C$ infection. Mayo Clin Proc 2004:79:51-6.

62 Vento S, Garofano T, Renzini C, et al. Fulminant hepatitis associated with hepatitis A virus superinfection in patients with chronic hepatitis C. NEngl J Med 1998;338:286-90.

63 Gebo KA, Chander G, Jenckes MW, et al. Screening tests for hepatocellular carcinoma in patients with chronic hepatitis $C$ : a systematic review. Hepatology 2002;36(suppl 1):S84-92.

64 Clifford BD, Donahue D, Smith L, et al. High prevalence of serological markers of autoimmunity in patients with chronic hepatitis C. Hepatology 1995:21:613-19.

65 Cassani F, Cataleta M, Valentini $P$, et al. Serum autoantibodies in chronic hepatitis C: comparison with autoimmune hepatitis and impact on the disease profile. Hepatology 1997;26:561-6.

66 Marazuela M, Garcia-Buey L, Gonzalez-Fernandez B, et al. Thyroid autoimmune disorders in patients with chronic hepatitis $C$ before and during interferon-alpha therapy. Clin Endocrinol 1996;44:635-42.

67 Pariante CM, Orru MG, Baita A, et al. Treatment with interferon-alpha in patients with chronic hepatitis and mood or anxiety disorders. Lancet 1999;354:131-2
68 Fontana RJ, Hussain KB, Schwartz SM et al. Emotional distress in chronic hepatitis C patients not receiving antiviral therapy. J Hepatol 2002;36:401-7. 69 Stedman C. Herbal hepatotoxicity. Semin Liver Dis 2002;22:195-206.

70 International Interferon-alpha Hepatocellular Carcinoma Study Group. Effect of interferon-alpha on progression of cirrhosis to hepatocellular carcinoma: a retrospective cohort study. Lancet 1998;351:1535-9.

71 Ikeda K, Saitoh S, Arase Y, et al. Effect of interferon therapy on hepatocellular carcinogenesis in patients with chronic hepatitis type C: a long-term observation study of 1,643 patients using statistical bias correction with proportional hazard analysis. Hepatology 1999:29:1 124-30.

72 Yoshida H, Arakawa Y, Sata M, et al. Interferon therapy prolonged life expectancy among chronic hepatitis $C$ patients. Gastroenterology 2002; 123:483-91

73 Poynard T, McHutchison J, Manns M, et al. Impact of pegylated interferon alfa- $2 \mathrm{~b}$ and ribavirin on liver fibrosis in patients with chronic hepatitis $\mathrm{C}$. Gastroenterology 2002;122:1303-13.

74 Imazeki F, Yokosuka O, Fukai K, et al. Favorable prognosis of chronic hepatitis $C$ after interferon therapy by long-term cohort study. Hepatology 2003:38:493-502.

75 Karnam US, Reddy KR. Pegylated interferons. Clin Liver Dis 2003:7:139-48.

76 Fried MW, Shiffman ML, Reddy KR, et al. Peginterferon alfa-2a plus ribavirin for chronic hepatitis C virus infection. N Engl J Med 2002;347:975-82.

77 Manns MP, McHutchison JG, Gordon SC, et al. Peginterferon alfa-2b plus ribavirin compared with interferon alfa- $2 b$ plus ribavirin for initial treatment of chronic hepatitis C: a randomised trial. Lancet 2001;358:958-65.

78 Torriani FJ, Rodriguez-Torres M, Rockstroh JK, et al. Peginterferon alfa-2a plus ribavirin for chronic hepatitis $C$ virus infection in HIV-infected patients. N Engl J Med 2004;351:438-50.

79 Chung RT, Andersen J, Volberding P, et al. Peginterferon alfa-2a plus ribavirin versus interferon alfa-2a plus ribavirin for chronic hepatitis $C$ in HIVcoinfected persons. N Engl J Med 2004;351:451-9.

80 Perronne C, Carrat F, Bani-Sadr F, et al. RIBAVIC (ANRS HCO2): a randomized controlled trial of pegylated-interferon alfa- $2 \mathrm{~b}$ plus ribavirin versus interferon alfa- $2 \mathrm{~b}$ plus ribavirin for the initial treatment of chronic hepatitis $\mathrm{C}$ in HIV co-infected patients. Eleventh conference on retroviruses and opportunistic infections, San Francisco, California, 2004: No 117.

81 Zarski JP, Mc Hutchison J, Bronowicki JP, et al. Rate of natural disease progression in patients with chronic hepatitis C. J Hepatol 2003;38:307-14.

\section{Management of chronic renal failure}

This course will be held on 19-22 September 2005 at the University of Warwick. Further information is from Dr Charlotte Moonan, Department of Biological Sciences, University of Warwick, Coventry CV4 7AL, UK. Tel: 0247652 3540; email: Charlotte.Moonan@ warwick.ac.uk. 